\title{
A propósito de José Guimón
}

\author{
About José Guimón
}

Antonio Espino Granado

Médico Psiquiatra.

Correspondencia: Antonio Espino (to.pino@telefonica.net)

Iñaki MARKEZ (2018), José Guimón. Historias de un arquitecto de la psiquiatría y psicología vascas, Bilbao, Bizkaiko Foru Aldundia/Diputación Foral de Bizkaia y Ekimen Editorial. ISBN: 978-84-7752-631-5, 450 páginas.

$\mathrm{E}^{\mathrm{s}}$ LIBRo QUe HA DEDICADO IÑAKI MARKez a la vida y la obra de José Guimón trata de ser, a la vez, un homenaje a su trayectoria y a su persona, y un recordatorio detallado de lo que significó su tarea como psiquiatra en el contexto de su territorio, Vizcaya y el País Vasco, en un momento de renovación general de la vida política de nuestro país y también de la propia psiquiatría española después de la dictadura.

Su lectura nos ayuda a conocer mejor a José Guimón y, también, los procesos ocurridos dentro de la salud mental en el País Vasco en todos estos años, donde Guimón ha tenido extraordinario protagonismo. También a conocer algunos aspectos relativos a la posición y procedencia de su familia dentro de Vizcaya, especialmente su padre, médico de éxito represaliado en la Guerra Civil, y su hermano mayor, implicado en momentos de especial dificultad en la política vasca desde posiciones democristianas y ajenas al nacionalismo. Padre y hermano especialmente queridos por José Guimón.

Menos nos va a contar Markez sobre los avatares políticos del propio Guimón, que vivió momentos delicados en el País Vasco, causados por el progresivo enfrentamiento interno de la sociedad y las actividades de la banda terrorista ETA -que, partiendo de acciones selectivas, alcanzarían a sectores cada vez más amplios de la 
población, pudiendo afectar a la seguridad de cualquier familia por el solo hecho de ser conocida y reconocida, tener algún miembro de prestigio o disponer de suficiente solvencia económica-. Acaso por haber vivido con especial interés y preocupación la situación por la que atravesó el pueblo vasco durante todos esos años -los burgaleses siempre hemos tenido una relación especial con los bilbaínos-, me quedo con las ganas de haber sabido más sobre la actitud con que Guimón hubo de afrontar esta situación, muy especialmente pensando en la seguridad de su mujer y sus dos hijos.

A pesar de la discreción con la que siempre se condujo Guimón en este aspecto, recuerdo una conversación en Madrid, estando yo en el Ministerio de Sanidad, sobre la situación de violencia en el País Vasco. Y recuerdo, aunque algo vagamente, una conversación con Guimón, ya entonces catedrático de Psiquiatría, donde me expresó las dificultades existentes en el País Vasco para poder desarrollar con un margen de tranquilidad todos sus proyectos, al punto de haberse planteado como opción trasladarse a Barcelona, donde había estudiado y mantenía estupendas relaciones con personas del mundo académico. De aquella conversación recuerdo igualmente haberle dejado caer la posibilidad de venir temporalmente a Madrid y hacerse cargo del Psiquiátrico de Leganés, dependiente del Ministerio de Sanidad a través de uno de sus organismos autónomos, la AISNA (Administración Institucional de la Sanidad Nacional). Opción que Guimón agradeció y se comprometió a pensar, aunque no creo que llegara nunca a hacerlo. Supongo que su posterior marcha a Suiza, junto a la continuidad en su carrera académica y profesional, le habría de aportar mayor seguridad a él y su familia.

Mis contactos con Guimón se habían iniciado estando ya en el Ministerio, de la mano del núcleo de psicoanalistas del Hospital Psiquiátrico de Leganés y, más en concreto, a través de Luis Guzmán -candidato entonces como Guimón al reconocimiento oficial como psicoanalista-, quien junto con José Jaime Melendo y por petición expresa de Guimón -responsable ya entonces del Servicio de Psiquiatría del Hospital de Basurto- venían haciendo tareas de supervisión en las instituciones psiquiátricas vascas. Por entonces, todo lo relacionado con el desarrollo de grupos terapéuticos desde múltiples perspectivas y enfoques era "trending topic" en Leganés al considerarlo una buena alternativa a seguir, frente a las psicoterapias individuales, en la atención sanitaria pública.

Mi relación con José Guimón fue corta en el tiempo, profesional e intensa, al coincidir a lo largo de su participación en asuntos generales de cambio en la formación y las reformas de la asistencia psiquiátrica espańola, aspectos frente a los que siempre tuvo una sensibilidad especial. Nuestra relación iría disminuyendo al dejar por mi parte el Ministerio y muy especialmente con su traslado a la Cátedra de Ginebra.

Nos volvimos a ver y tuvimos ocasión de conversar con cierta calma, sin embargo, en 2005, en un encuentro en Toledo, promovido por Fernando Lamata -vi- 
cepresidente entonces del Gobierno de Castilla la Mancha-, para celebrar los 20 años del Informe de la Comisión Ministerial para la Reforma Psiquiátrica y su entrega al ministro de Sanidad y Consumo Ernest Lluch, catalán y amigo del pueblo vasco, asesinado por ETA en el año 2000, en el garaje de su casa en Barcelona.

Creo que fue la última vez que tuve ocasión de compartir recuerdos con Pepe Guimón y conservo de aquel último encuentro una nota manuscrita suya sobre un ejemplar original del Informe de la Comisión, con su letra "de médico" y donde expresaba, una vez más, su talante afectuoso y su generosidad: "Me encantó participar en una ilusionante aventura que lideraste. J. Guimón”.

El libro de Markez, centrado en la trayectoria de Guimón como impulsor y "patrón" de la psiquiatría vasca en estos años de cambio, incluye sus actividades relacionadas con el Gobierno de España -su participación en la Comisión Ministerial para la Reforma Psiquiátrica y en la Comisión Nacional de la Especialidad de Psiquiatría-, sin bajar al detalle. Sin embargo, es de justicia señalar que la aportación de Guimón en este ámbito también fue, aunque mucho más breve, importante.

Los procesos de elaboración del Informe de la Comisión Ministerial para la Reforma Psiquiátrica y del nuevo Programa de Formación de Especialistas de Psiquiatría tuvieron continuidad en el tiempo. En octubre de 1984, Pedro Sabando, subsecretario del Ministerio y presidente de la Comisión Ministerial para la Reforma Psiquiátrica creada por Orden de 27 de julio de 1983, remite una carta a todas las personas, previa a su designación como vocales de la Comisión Ministerial, invitándoles a participar en la misma. José Guimón contestará a Pedro Sabando a vuelta de correo: "Distinguido amigo. Recibo hoy su atta. del 3 de octubre por la que me invita a formar parte como vocal de la Comisión Ministerial para la Reforma Psiquiátrica. Acepto muy honrado su proposición y le expreso mis deseos de, en caso de ser designado, colaborar con el mayor entusiasmo en tan importante proyecto. Atentamente le saluda, José Guimón Ugartechea”.

A partir de su aceptación y con fecha de 26 de noviembre, remití una carta a cada vocal agradeciendo su participación y convocándoles el 14 de diciembre en la Subsecretaría del Ministerio para constituir la Comisión, adjuntándoles un "Documento de Política Psiquiátrica” elaborado por la Secretaría de la Comisión que pudiera servir de apoyo a los trabajos de la misma. En la reunión constituyente se acordó tomar como documento base el elaborado y presentado por el secretario de la Comisión, iniciando ya en esta primera reunión la lectura y discusión del mismo.

El criterio seguido para la elección de los siete vocales de la Comisión había sido intentar aunar y complementar territorios, profesiones, ámbitos de actuación profesional y académica y distintos campos específicos dentro de la especialidad, además de contar con garantías de entendimiento entre sus miembros para poder llevar a buen fin la tarea encomendada. En Guimón, se tuvo en cuenta muy especialmente su 
condición de catedrático de Psiquiatría "de nuevo tipo", su pertenencia al País Vasco -donde junto a su prestigio venía colaborando con el Gobierno Vasco en la Reforma Psiquiátrica-, su vinculación con el mundo psicoanalítico y su actitud política abierta a facilitar y promover cambios institucionales en la atención a la salud mental.

José Guimón participó intensa y lealmente en las tareas de la Comisión. Ya en enero de 1985 remitirá un documento con "Observaciones sobre el Documento de Política Psiquiátrica” al secretario de la Comisión, incorporando un Anexo Documental que recogía en gran medida su experiencia tanto de Nueva York como de sus tareas en el País Vasco. Aportaba cuatro libros editados por el Departamento de Sanidad y Seguridad Social del Gobierno Vasco (Legislación psiquiátrica: critica y alternativas; Psiquiatría infantil; Plan de asistencia y salud mental y Población hospitalaria psiquiátrica años 80-81) y dos documentos: III Solicitud de ayuda de cooperación institucional presentada al Comité Conjunto Hispano-Americano para la cooperación cultural y educativa y Final report of the governor's select commision on the future on the state-local mental health system (Jerome M. Goldsmith, 1984).

Analizar el impacto de las Observaciones presentadas por Guimón y su participación directa en los debates sobre el redactado final sería objeto, seguramente, de un artículo específico. En todo caso, la lectura actual de sus observaciones sigue impresionando por su coherencia y ecuanimidad. En relación al acelerado momento autonómico, especialmente marcado en el País Vasco, "urge dictar pronto las normas de carácter general en salud mental para que se incluyan en la Ley de Sanidad que prepara el Ministerio"; sobre la necesidad de dar continuidad a las reformas, "será necesario crear una Oficina Estatal de la Asistencia Psiquiátrica con presupuesto propio"; o respecto de determinados cambios en aspectos concretos del texto y que serían recogidos, incluir "la precariedad de recursos asistenciales comunitarios" o "mencionar explícitamente que se realizarán esfuerzos en la rehabilitación", algo que aparecerá en la Ley de Sanidad; o en cuanto al propio ritmo y dificultades ligadas a las reformas, "se menciona que las unidades de hospitalización estarán integradas en la red de servicios de salud del área y creo que conviene añadir en lo posible", asunto que se verá resuelto en el texto final del documento al incluir el concepto de integración funcional. Y otros muchos aspectos menores sobre los que incidió positivamente en las tareas de elaboración del Informe final.

El 27 de marzo tuvimos la última reunión de la Comisión dedicada a las correcciones relativas a la propuesta de recomendaciones presentada por el secretario de la misma. Y en abril disponíamos ya de un redactado final del Informe para su entrega al Ministro de Sanidad, quien lo presentaría formalmente a los medios el 4 de junio, ya pasado por la imprenta.

Pues bien, el 29 de abril de 1985 se va a constituir la nueva Comisión Nacional de la Especialidad de Psiquiatría resultado de la aprobación del Real Decreto de 
11 de enero de 1984. La Comisión estaba constituida por tres miembros propuestos por el Ministerio de Sanidad (Carlos Castilla, Valentín Corcés y Antonio Espino), tres por el Ministerio de Educación (Carles Ballús, José Guimón y Alberto Izquierdo), dos elegidos por los MIR (Ana Castaño y Joaquín González), dos por las asociaciones científicas (Víctor Aparicio por la AEN y López Ibor por la SEP) y uno por el Consejo General de Médicos (José Luis Gutiérrez). En esa primera reunión, los vocales debían elegir al presidente y al secretario de la misma. Habían disculpado su asistencia vía telegrama Carlos Castilla y el profesor Ballús, catedrático de Barcelona. Carlos Castilla daba su voto de forma expresa a Guimón para presidente y a Espino para secretario. Carles Ballús, por su parte, delegaba su voto en José Guimón. Ya en la reunión constitutiva, Guimón sería el único propuesto para presidente, siendo propuestos para el puesto de secretario Espino y López Ibor, saliendo elegido el primero en la votación realizada.

La tarea de Guimón al frente de la Comisión fue, a mi juicio, de extraordinaria importancia, entre otras cosas, por haber sabido orientar el inicio de todo un conjunto de cambios en la línea en la que se había movido el Informe de la Comisión para la Reforma. No en vano, el presidente y el secretario, junto con Valentín Corcés, habían formado parte de la misma. La Comisión de la Especialidad hubo de afrontar multitud de asuntos cotidianos junto a otros de mayor calado: las condiciones de acreditación de las unidades docentes de la especialidad, el nuevo programa docente o la evaluación de los MESTOS de psiquiatría -los más numerosos-, a efectos de convalidarles la especialidad. Una tarea que daría por concluida Guimón una vez publicada la Guía de formación de médicos especialistas en octubre de 1986.

Sobre la gestión realizada por el presidente Guimón y su actitud siempre independiente y favorecedora de consensos, quiero destacar la convocatoria especial de la Comisión llevada a cabo los días 13 y 14 de diciembre de 1985 para afrontar las bases del nuevo programa de la especialidad de psiquiatría. En dichas jornadas, los dos MIR analizaron el programa vigente; Guimón, junto con el sociólogo Enrique Sacanell, nos mostraron los resultados de la encuesta que habían llevado a cabo con los responsables de los centros acreditados para la docencia; Guimón se encargó personalmente de elaborar un informe acerca de los estudios realizados en España con propuestas de mejora de la formación de residentes y el Dr. Ballús, por último, desarrolló un informe sobre los programas de residencia en psiquiatría de los países de la Comunidad Económica Europea (CEE). El último punto -y principal- de la jornada del sábado 14 sería, precisamente, la discusión entre los miembros de la Comisión de la especialidad sobre los principales cambios que había que introducir en el programa vigente.

A partir de aquí, el nuevo programa aprobado por la Comisión Nacional de la Especialidad y publicado en octubre de 1986 fue guiado con contundencia y ce- 
leridad por Guimón, una vez aclarado entre todos el objetivo a seguir, no sin ciertas dificultades encontradas en su desarrollo, principalmente por la existencia de posiciones encontradas entre los miembros de la Comisión en cuanto a la inclusión de forma más o menos radical de los elementos de la nueva psiquiatría de orientación comunitaria en el programa docente.

Quede como última anécdota la decisiva intervención de Guimón en la puesta en marcha de la siguiente Comisión Nacional. Yo había sido confirmado nuevamente como miembro de la Comisión por parte del Ministerio de Sanidad y Guimón me comentó que sería conveniente que pudiera sustituirle en la Presidencia y continuar así las tareas emprendidas en la organización y contenidos de la formación de los psiquiatras en España. Aun agradeciendo su confianza, veía difícil obtener los votos para sustituirle en la presidencia y así se lo dije. Guimón se encargó personalmente de hablar con algún miembro de la Comisión, en concreto con Carlos Castilla, que no tenía interés alguno en ocupar dicho puesto. De forma que en la reunión de constitución de la nueva Comisión, de la que había entrado a formar parte por el Ministerio de Sanidad Manuel Desviat, este propuso a Carlos Castilla como presidente para sustituir a Guimón. Pero Carlos señaló sus muchas ocupaciones para poder hacerse cargo y propuso mi nombre, que nadie rechazó. Yo propuse entonces como Secretario a Tiburcio Angosto, que había entrado a formar parte de la Comisión en representación de la AEN, y que también fue aceptado.

De vuelta al libro de Ińaki Markez y para concluir, quisiera que estos recuerdos de aquella época "ocurridos en los territorios del centro" y que me han ido surgiendo de su lectura puedan ayudar a entender mejor el importante papel jugado por Guimón en ese momento de cambios tan crucial que fueron los 80 en el conjunto del país y en el ámbito de nuestra profesión. Guimón colaboró de manera contundente durante el primer gobierno socialista, precisamente cuando era más útil, sin duda, su colaboración. Y quisiera que estos recuerdos, por último, puedan ayudar a complementar y apuntalar la inmensa tarea realizada a lo largo de su vida profesional para la psiquiatría del País Vasco, algo que Markez ha desarrollado con especial detalle y tino en el libro.

En todo caso, el libro de Markez supone también, sin ninguna duda, un acto de reconocimiento con el que, verdaderamente, sería muy difícil no coincidir. 